\title{
Evaluation of coronal shift as an indicator of neuroaxial abnormalities in adolescent idiopathic scoliosis: a prospective study
}

Mohsen Karami ${ }^{1 *}$, Soodeh Sagheb ${ }^{2}$ and Keyvan Mazda ${ }^{3}$

\begin{abstract}
Background: In previous studies, many indicator factors have been proposed to select patients who need an MRI screening of the spinal canal. In current study, the clinical and radiologic factors including coronal parameters of the curve were evaluated to find out which indicator is more important.

Methods: A prospective study included 143 consecutive patients with the diagnosis of adolescent idiopathic scoliosis who were treated between 2010 and 2013 at our spinal clinics. Only patients with normal or subtle neurologic findings were included. All patients were evaluated by a total spine MRI protocol for examination of neuroaxial abnormalities. Known indicators and also coronal shift were analysed in all patients with or without abnormal MRI.

Results: The incidence of neuroaxial abnormalities was $11.9 \%$ (17 of 143); only 5 patients (3.5\%) were operated to treat their neuroaxial problem. The significant indicators of the abnormalities in our patients were: younger age at onset, asymmetric superficial abdominal reflex and, coronal shift more than $15 \mathrm{~mm}(P=0.03)$. Some previously known indicators like atypical curves, male gender, double curves and absence of thoracic lordosis were not different between two groups of the patients.
\end{abstract}

Conclusions: A total spine MRI is recommended at presentation in patients with younger age, abnormal neurologic findings and severe coronal shift.

Keywords: Scoliosis, Chiari malformation, Magnetic resonance imaging, Syringomyelia

\section{Background}

Although the etiology of "idiopathic" scoliosis is still uncertain, the association between scoliosis and neuroaxial abnormalities such as syringomyelia or Chiari malformations has been well established. With the development of Magnetic Resonance Imaging (MRI), neuroaxial abnormalities are increasingly being found in patients with idiopathic scoliosis. Many associated clinical signs and radiologic parameters have been considered as indicators of neuroaxial abnormalities in these patients. Because of the uncertainty of the correlation among these parameters and the existing of neuroaxial anomalies, many surgeons prefer to perform MRI study on all idiopathic scoliosis patients.

\footnotetext{
* Correspondence: mnkarami@gmail.com

${ }^{1}$ Talegani Hospital, Shahid Beheshti University of Medical Sciences, Tehran, Iran

Full list of author information is available at the end of the article
}

Although all of the detected abnormalities may not require active intervention, preoperative detection is important in patients who are undergoing manipulative correction [1-4]. The most sensitive way to investigate neuroaxial abnormalities is MRI. But its routine use remains controversial, and current indications to perform MRI in "idiopathic" scoliosis vary from center to center.

The goals of this study were to (a) document the incidence of neuroaxial abnormalities in adolescent idiopathic scoliosis and (b) study the association of neuroaxial abnormalities with the curve characteristics such as coronal shift.

\section{Materials and methods}

We prospectively studied 143 patients who were diagnosed as Adolescent Idiopathic Scoliosis (AIS) and were admitted at our university hospitals between 2010-2013. 
AIS was considered when the beginning of the disease was between age of 10 and 16 . These patients were selected after excluding those with failure of formation or segmentation of the spine on plain radiographs (congenital scoliosis), those with associated conditions or syndromes and those who have had neurologic findings on their clinical examination other than Asymmetric Superficial Abdominal Reflex (ASAR).

Every scoliosis patient has been studied at our institutions based on our established "spine protocol". It includes a throughout history taking and physical examination, standing potero-anterior and lateral radiographs as well as bending and tractional films and laboratory tests including coagulation tests. The x-rays have been taken using SRS recommendations [5]. Total spine MRI is also included in the protocol for every patient. The radiographs have been studied by the SpineView software to measure coronal and sagittal curves angles. Coronal shift, Lenke [6] and King classification [7] were also determined by the software.

Coronal plane curve patterns were classified as high thoracic, thoracic, thoracolumbar or lumbar curves on the basis of the location of the apexes. Each existing curve has been marked by one operator and the measurements were done by the software.

Total spine MRI was obtained and was interpreted by an experienced radiologist for any abnormalities in the brainstem and spinal cord. Arrnold chiari-I malformation was considered when the tonsillar herniation was $5 \mathrm{~mm}$ or more below the level of foramen magnum. Location and dimensions of the syringomyelia was also noted and the level of conus medullaris was documented. In doubtful cases, MRI with Gadolinium was also obtained to better define existing abnormalities. The presence and type of anomaly in the MRI were correlated to the age at presentation, curve characteristics (sagittal and coronal profiles), typing of scoliosis and so on.

\section{Statistical analysis}

Two different groups of patient were defined. First group, in whom MR imaging revealed neuroaxial abnormalities and the second group, in whom total spine MRI was normal. All variables were compared in these two groups using one way ANOVA and the Fisher exact test. The differences with a $P$ value of $<0.05$ were considered as statistically significant.

\section{Results}

Our patients consist of 143 patients who were diagnosed as having AIS at their presentation. The patients were classified according to Lenke and King classification. The most frequent type according to Lenke classification was type one in 70 patients (49\%) followed by type two in 44 patients $(30.7 \%)$ and then type 5 in 16 patients
(11.2\%), type 4 and 6 each one in 5 patients (3.5\%) and the least common type was type 3 in 3 patients (2\%). According to King classification, there were 55 patients (38.4\%) with type 2 which was the most frequent one and then was type 3 and 4 each one in 25 patients (17.5\%), 18 patients were type 5 (12.5\%), 15 patients $(10.5 \%)$ were unclassified and the least common type was type 1 in 5 patients (3.5\%). There were no significant difference among King and Lenke types and occurrence of neuroaxial abnormalities.

The incidence of neuroaxial abnormalities was $11.9 \%$ (17/143). The abnormalities related to disc or irregularity of the end plates (6 patients, 4\%) were not considered as neuroaxial abnormality. The most common neuroaxial abnormality was syringomyelia in thirteen patients (9.7\%), in which two were associated with Arnold-Chiari malformation type I (Table 1). The most frequent region of isolated syringomyelia was thoracic region (8 patients, $5.5 \%$ ).

The mean age at presentation was 13.9 (10.5-17) years in patients with neuroaxial abnormalities as compared to $14.9(10.7-19)$ years in those who did not have any abnormalities $(P=0.05)$.

Three curves were determined and measured as described by Lenke classification. The mean of the proximal thoracic curve was $28.2^{\circ}$ (range $8^{\circ}$ to $67^{\circ}$ ) in patients without neuroaxial problem and $19.6^{\circ}$ (range $17^{\circ}$ to $21^{\circ}$ ) in those who have had abnormalities. The middle thoracic curve was measured as $55.7^{\circ}$ (range $15^{\circ}$ to $128^{\circ}$ ) in patients without neuroaxial abnormalities as compared to $58.5^{\circ}$ (range $40^{\circ}$ to $85^{\circ}$ ) in those patients who have had abnormalities. These proximal and mid thoracic curves did not have any correlation with neuroaxial abnormalities. On contrary, lumbar or thoracolumbar curve mean was $39.6^{\circ}$ (range $13^{\circ}$ to $75^{\circ}$ ) in patients without abnormalities which was significantly less than those patient who had neuroaxial abnormalities with the mean of $53.5^{\circ}$ (range $39^{\circ}$ to $\left.67^{\circ}\right)(P$ value $=0.03)$ (Table 2$)$. The direction of the curves was not associated with the occurrence of neuroaxial abnormalities.

Sagittal profile of the spine was also evaluated in this study. Thoracic sagittal angles (T1-T12) as well as lumbar

Table 1 Detected neuroaxial abnormalities in patients with AIS

\begin{tabular}{lll}
\hline & Frequency & Percent \\
\hline Thoracic syringomyelia & 8 & 5.5 \\
Cervical syringomyelia & 2 & 1.4 \\
Arnold Chiari type I+ cervical s & 2 & 1.4 \\
syringomyelia & & \\
Isolated Arnold Chiari type I & 1 & 0.7 \\
Mild tonsillar herniation & 2 & 1.4 \\
Tetherd cord & 1 & 0.7 \\
Total & 17 & 11.9 \\
\hline
\end{tabular}


Table 2 Descriptive statistics in patients with or without abnormal MRI findings

\begin{tabular}{|c|c|c|c|c|c|}
\hline \multicolumn{2}{|c|}{ MRI* } & \multirow{2}{*}{$\begin{array}{l}\text { Minimum } \\
2\end{array}$} & \multirow{2}{*}{$\begin{array}{l}\text { Maximum } \\
62\end{array}$} & \multirow{2}{*}{$\frac{\text { Mean }}{26.21}$} & \multirow{2}{*}{$\begin{array}{l}\text { Std. deviation } \\
14.206\end{array}$} \\
\hline- & Thoracic sagittal angle & & & & \\
\hline & Lumbar sagittal angle & 13 & 67 & 45.02 & 12.732 \\
\hline & Age of patients & 10 & 19 & 14.91 & 1.943 \\
\hline & Main thoracic curve angle & 15 & 128 & 55.74 & 18.598 \\
\hline & Coronal shift & 0 & 56 & 18.56 & 13.810 \\
\hline & Proximal thoracic curve & 8 & 67 & 28.29 & 12.701 \\
\hline & Distal L/TL curve & 13 & 75 & 39.66 & 12.656 \\
\hline \multirow[t]{7}{*}{+} & Thoracic sagittal angle & 11 & 23 & 16.67 & 6.028 \\
\hline & Lumbar sagittal angle & 16 & 47 & 35.67 & 17.098 \\
\hline & Age of patients & 10 & 17 & 13.95 & 1.900 \\
\hline & Main thoracic curve angle & 40 & 85 & 58.57 & 16.440 \\
\hline & Coronal shift & 34 & 41 & 37.67 & 3.512 \\
\hline & Proximal thoracic curve & 17 & 21 & 19.67 & 2.309 \\
\hline & Distal L/TL curve & 39 & 67 & 53.50 & 14.059 \\
\hline
\end{tabular}

*MRI - : Negative neuroaxial abnormalities, +: Positive neuroaxial abnormalities.

sagittal angle were measured in both groups of patients. The mean of thoracic sagittal angle was $26.2^{\circ}$ (range $2^{\circ}$ to $62^{\circ}$ ) in all patients without neuroaxial abnormalities as compared to $16.7^{\circ}$ (range $11^{\circ}$ to $23^{\circ}$ ) in those patients who had abnormalities. This difference was not statically significant $(\mathrm{P}=0.2)$.

The major point in this study was the correlation between coronal imbalance and neuroaxial abnormalities. The mean of radiologic transverse coronal shift from plumb line was $18.5 \mathrm{~mm}$ (range 0 to $56 \mathrm{~mm}$ ) in patients without neuroaxial abnormalities which was significantly less than those who have had neuroaxial abnormalities with the mean of $37.6 \mathrm{~mm}$ (range 34 to $41 \mathrm{~mm}$ ) (P value = 0.02) (Table 2) (Figure 1). Significant radiological coronal imbalance was defined a $15 \mathrm{~mm}$ shift of C7 plumb line from Center Sacral Vertical Line (CSVL) by authors. There were 46 patients (32\%) who have had coronal imbalance. Thirteen patients among 17 patients who have had neuroaxial abnormalities, have had coronal shift of more than $15 \mathrm{~mm}$ that means two third of patients with abnormal MRI findings have had coronal imbalance $(P=0.03)$ odds ratio of $6.4,95 \%$ confidence interval 1.34-30.37.

On physical examination 6 patients (4.1\%), have had an Asymmetric Superficial Abdominal Reflex (ASAR). All of them had abnormal neuroaxial findings on MR imaging. Two patients who had Arnold Chiari malformation and cervical syringomyelia were operated for foramen magnum decompression before scoliosis correction. Their syringomyelia was disappeared after decompressive surgery. Patients with isolated syringomyelia (eight patients) or mild tonsillar herniation (less than $5 \mathrm{~mm}$ ) (two patients) with normal neurologic examination, underwent only a scoliosis surgery. None of them had neurologic complication during or after the surgery. Three patients, who had isolated syringomyelia with abnormal neurologic sign, underwent decompressive surgery by our neurosurgeon. Therefore only 5 patients $(3.5 \%)$ have been treated neurosurgically before the scoliosis surgery, all of them have had ASAR.

\section{Discussion}

The current guidelines for MRI screening in idiopathic scoliosis are not well defined, the recommended indications for performing MRI in the literature include early onset [8,9] atypical curvature [10-14], double thoracic curve (King type-5) [15,16], rapid progression [17], male gender [18], the absence of thoracic apical segment lordosis $[19,20]$ and abnormal neurologic findings [21,22]. However, the whole clinico-radiologic parameters of idiopathic scoliosis have not been studied yet.

We collected previous valuable studies about the indicators of the neuroaxial abnormalities in idiopathic scoliosis. The studies with more than 26 cases were summarized in Table 3 . These studies are mostly retrospective or prospective case series. The incidence of neuroaxial abnormalities was reported between 1.8 to $31 \%$ which depends on the inclusion criteria among various studies.

Higher incidences were reported in those studies that infantile and juvenile scoliosis were included $[8,22,26]$ as well as those studies in which all patients even with major neurologic signs such as hypereflexia, clonus and muscle weakness, were included $[8,30,32]$. In this study, only patients with minor neurologic sign (e.g. ASAR) were included, so the incidence of $11.7 \%$ of spinal cord abnormalities was reasonable. When the patients who underwent neurosurgical intervention were separated from the others, the incidence decreased to 5 patients 


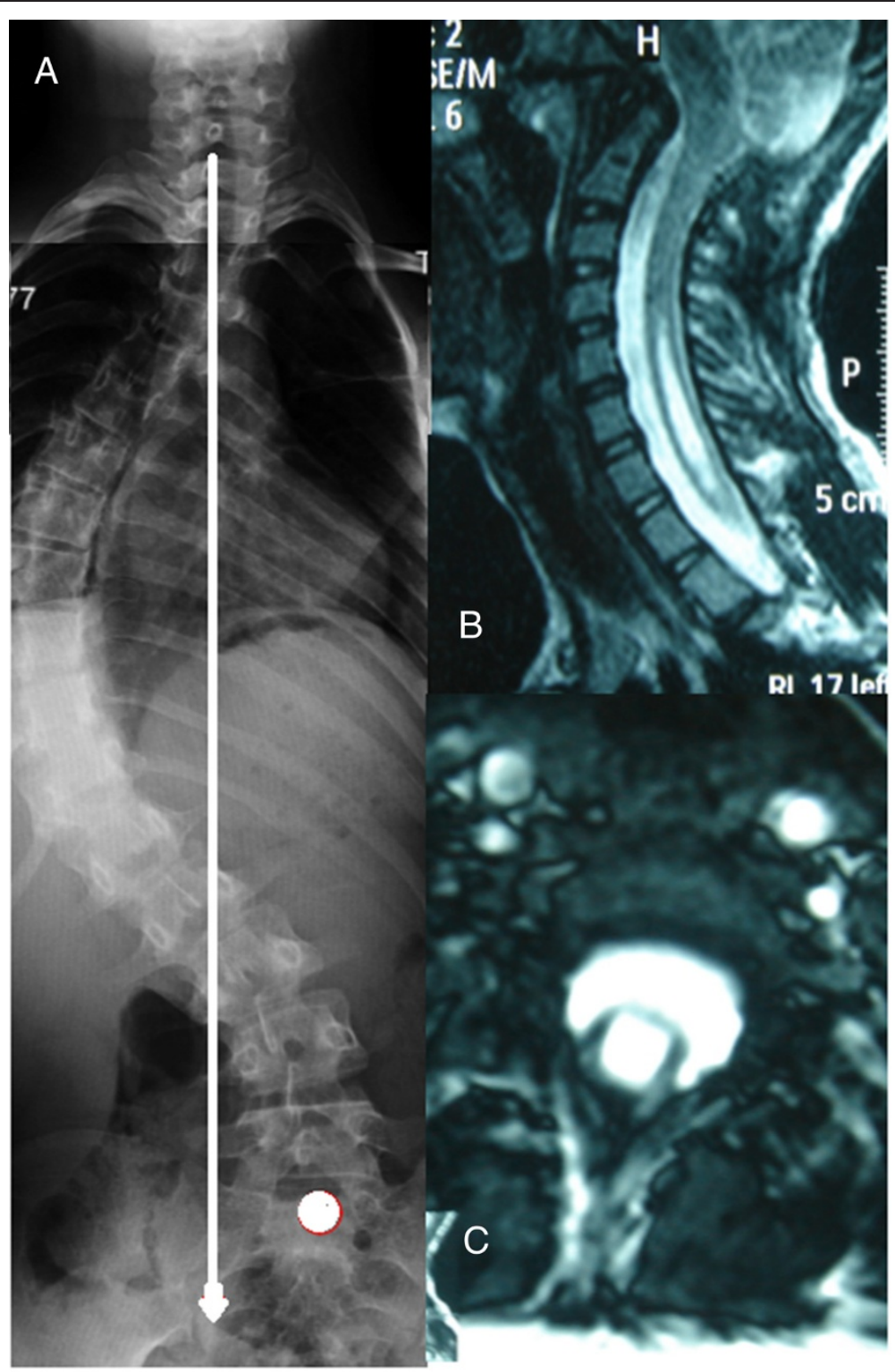

Figure 1 Twelve-year-old female patient with adolescent idiopathic scoliosis who underwent decompressive surgery for her neuroaxial abnormalities. A, Preoperative radiograph showed significant coronal imbalance. B, C, Preoperative MRI sections showing Arnold-Chiari Type I malformation and cervical syringomyelia.

(3.5\%). All of these patients have had ASAR. The others were not operated for their neuroaxial abnormalities; no neurologic deterioration was detected after their scoliosis surgery.

Regarding the age of the patients, younger age at presentation was considered in most studies as an indicator of neuroaxial abnormalities (Table 3) [30-32]. Although adolescent idiopathic scoliosis was only included in the study, the younger age at presentation was significantly correlated with abnormal neuroaxial abnormalities $(P=0.05)$. It has been concluded that earlier onset scoliosis is associated with a high incidence of neuroaxial abnormalities.

Another important factor is the gender. Male sex has been considered in three studies as a significant factor $[27,30,31]$ but the others did not agree $[8,26,29]$. Our study could not have revealed the correlation between male gender and abnormal neuroaxial findings.

Atypical curves (curves other than right thoracic major curve) were also studied by many authors but existing studies were reported controversial results (Table 3). Our study was not able to find a significant correlation 
Table 3 Short description of previous studies

\begin{tabular}{|c|c|c|c|c|c|c|c|c|c|c|c|c|c|c|}
\hline Study & $\begin{array}{l}\text { Type of } \\
\text { study }\end{array}$ & $\begin{array}{l}\text { Study } \\
\text { group }\end{array}$ & $\begin{array}{l}\text { No of } \\
\text { patient }\end{array}$ & $\begin{array}{l}\text { Neurologic } \\
\text { exams }\end{array}$ & $\begin{array}{l}\text { MRI } \\
\text { protocol }\end{array}$ & $\begin{array}{l}\text { Neuroaxial } \\
\text { problem\% }\end{array}$ & Age & Sex & $\begin{array}{l}\text { Atypical } \\
\text { curves }\end{array}$ & curve magnitude & $\begin{array}{l}\text { Double } \\
\text { curve }\end{array}$ & $\begin{array}{l}\text { Neurologic } \\
\text { findings }\end{array}$ & Pain & $\begin{array}{l}\text { Thoracic } \\
\text { kyphosis }\end{array}$ \\
\hline Geissele et al. & Prospective & $\mathrm{AIS}^{*}$ & 27 & NRt & Brain & $27 \%$ & NR & $N R$ & NR & NSD $\neq$ & NR & NR & NR & NR \\
\hline Spine 1991 [23] & & & & & & & & & & & & & & \\
\hline $\begin{array}{l}\text { Evans et al. JBJS-B } \\
1996 \text { [8] }\end{array}$ & Prospective & $J I S+$ AlS* $^{*}$ & 31 & $\begin{array}{l}\text { Nystagmus, } \\
\text { Ataxia, ASAR }\end{array}$ & $\begin{array}{l}\text { Total } \\
\text { spine }\end{array}$ & $31 \%$ & NSD & NSD & $\begin{array}{l}\text { SD } ¥ \text {, left } \\
\text { curves }\end{array}$ & NR & NR & NSD & NR & NR \\
\hline $\begin{array}{l}\text { Mejia et al. JPO } \\
1996 \text { [24] }\end{array}$ & Prospective & $\mathrm{JIS}+\mathrm{AIS}$ & 29 & Only NL exams & $\begin{array}{l}\text { Total } \\
\text { spine }\end{array}$ & $7 \%$ & $N R$ & NR & $\begin{array}{l}\text { Only left } \\
\text { curves }\end{array}$ & NR & NR & NR & NR & NR \\
\hline $\begin{array}{l}\text { Shen et al. } \\
\text { JPO } 1996 \text { [25] }\end{array}$ & Prospective & AIS & 72 & Only NL exams & $\begin{array}{l}\text { Total } \\
\text { spine }\end{array}$ & $4 \%$ & NR & NR & NR & NR & NR & NR & NR & NR \\
\hline $\begin{array}{l}\text { Maiocco et al. } \\
\text { Spine } 1997 \text { [16] }\end{array}$ & Prospective & AIS & 45 & Only NL exams & $\begin{array}{l}\text { Total } \\
\text { spine }\end{array}$ & $4 \%$ & $N R$ & NR & NR & NR & NR & NR & NR & NR \\
\hline $\begin{array}{l}\text { Winter et al. Spine } \\
1997 \text { [10] }\end{array}$ & $\begin{array}{l}\text { Prospective } \\
\text { double blind }\end{array}$ & AIS & 140 & Only NL exams & $\begin{array}{l}\text { Total } \\
\text { spine }\end{array}$ & $2.8 \%$ & NR & NR & $\begin{array}{l}\text { Rt curves } \\
\text { included }\end{array}$ & NR & NR & NR & NR & NR \\
\hline $\begin{array}{l}\text { Gupta et al. Spine } \\
1998 \text { [22] }\end{array}$ & $\begin{array}{l}\text { Prospective + } \\
\text { retrospective }\end{array}$ & $\| S^{*}+J S$ & 98 & Only NL exams & $\begin{array}{l}\text { Total } \\
\text { spine }\end{array}$ & $18-20 \%$ & NR & NR & NR & NR & NR & NR & $N R$ & NR \\
\hline $\begin{array}{l}\text { Dobbs et al. JBJS-A } \\
2002 \text { [26] }\end{array}$ & Retrospective & $\| S$ & 46 & Only NL exams & $\begin{array}{l}\text { Total } \\
\text { spine }\end{array}$ & $21.7 \%$ & NSD & NSD & NSD & NSD & NR & NR & NR & $N R$ \\
\hline $\begin{array}{l}\text { Ouellet et al. Spine } \\
2003 \text { [27] }\end{array}$ & Retrospective & $\mathrm{JIS}+\mathrm{AIS}$ & 93 & NR & $\begin{array}{l}\text { Total } \\
\text { spine }\end{array}$ & NR & NSD & SD, male & $\begin{array}{l}\text { SD, left } \\
\text { curves }\end{array}$ & NR & NR & NR & NR & SD \\
\hline $\begin{array}{l}\text { Do et al. JBJS-A } \\
2003 \text { [28] }\end{array}$ & Prospective & AIS & 327 & Only NL exams & $\begin{array}{l}\text { Total } \\
\text { spine }\end{array}$ & $1.8 \%$ & $N R$ & NR & NR & NR & NR & NR & NR & NR \\
\hline $\begin{array}{l}\text { Davids et al. JBJS-A } \\
2004 \text { [29] }\end{array}$ & Retrospective & AIS & 274 & $\begin{array}{l}\text { Clonus, abnormal } \\
\text { reflexes, muscle } \\
\text { weakness, or cavus } \\
\text { foot }\end{array}$ & $\begin{array}{l}\text { Total } \\
\text { spine }\end{array}$ & $\begin{array}{l}2 \% \text { entire } \\
\text { cohort, 10\% } \\
\text { of selected } \\
\text { patients }\end{array}$ & NSD & NSD & NSD & NSD & NSD & NSD & NSD & SD \\
\hline $\begin{array}{l}\text { Inoue et al. Spine } \\
2005 \text { [30] }\end{array}$ & Prospective & All group & 250 & $\begin{array}{l}\text { Hyperactive reflex, } \\
\text { ASAR, Muscle } \\
\text { atrophy, sensory } \\
\text { loss, clonus }\end{array}$ & $\begin{array}{l}\text { Total } \\
\text { spine }\end{array}$ & $18 \%$ & $\begin{array}{l}\text { SD, Early } \\
\text { onset < } 11 \text { ys }\end{array}$ & SD, male & $\begin{array}{l}\text { SD, left } \\
\text { curves }\end{array}$ & NR & NR & $\begin{array}{l}\text { SD- all abnormal } \\
\text { neurologic finding }\end{array}$ & SD & $\begin{array}{l}\text { SD, Kyphois } \\
>30^{\circ}\end{array}$ \\
\hline $\begin{array}{l}\text { Nakahara et al. } \\
\text { Spine } 2010 \text { [31] }\end{array}$ & Retrospective & $\mathrm{JIS}+\mathrm{AIS}$ & 472 & Only ASAR & $\begin{array}{l}\text { Total } \\
\text { spine }\end{array}$ & $3.8 \%$ & $\begin{array}{l}\text { SD-Early } \\
\text { onset < } 11 \text { ys }\end{array}$ & SD-Male & NSD & SD & NR & SD & $N R$ & SD \\
\hline $\begin{array}{l}\text { Rajasekaran et al. } \\
\text { Indian J Orthop } \\
2010 \text { [32] }\end{array}$ & Retrospective? & All group & 94 & $\begin{array}{l}\text { Muscle weakness, } \\
\text { wasting ,ASAR, } \\
\text { Babinski }\end{array}$ & $\begin{array}{l}\text { Total } \\
\text { spine }\end{array}$ & $16 \%$ & $\begin{array}{l}\text { SD-Early } \\
\text { onset < } 11 \text { ys }\end{array}$ & NR & NSD & NSD & SD & SD & NR & SD \\
\hline
\end{tabular}

*AIS: Adolescent Idiopathic Scoliosis, JIS: Juvenile Idiopathic Scoliosis, IIS: Infantile Idiopathic Scoliosis. ${ }^{* * A S A R: ~ A s y m m e t r i c ~ S u p e r f i c i a l ~ A b d o m i n a l ~ R e f l e x . ~ † N R: ~ N o t ~ R e p o r t e d ~ i n ~ t h e ~ a r t i c l e . ~ ‡ N S D: ~ N o ~ S i g n i f i c a n t ~}$ Difference. ¥SD: Significant Difference. 
among various types of curves and direction of the curves with the abnormal neuroaxial findings.

The curve magnitude at presentation was also studied in the literature. But no significant correlation with neuroaxial abnormalities was found in most of them (Table 3) neither in our study [23,26,29,32,33].

There are controversial results according to Davis et al. [29] and Rajasekaran [32] about the double major curves and existing neuroaxial abnormalities. According to our results, more severe lumbar or thoracolumbar curves could increase the probability of neuroaxial abnormalities $(P=0.03)$. Qiao et al. also reported more frequent neural axis abnormalities in thoracolumbar curves [34].

In most studies, persistence of neurologic signs correlates significantly with abnormal MRI findings [30-32]. In our study, we only selected patients with minor neurologic sign (e.g. ASAR), all patients with ASAR has had abnormal MRI findings and most of them were operated by our neurosurgeon.

Absence of thoracic kyphosis is an inherent character of idiopathic curves. Thoracic kyphosis or loss of apical segmental lordosis has been considered recently as an important indicator of an existing neuroaxial abnormality [27,29-32]. Our study was not able to confirm this correlation $(p=0.2)$.

The other indicator which was the focus of our study is the coronal shift. Lee et al. studied the correlation between coronal balance and neuroaxial abnormalities [33], but in their study neurologic examination and presence of ASAR have not been mentioned. They defined coronal imbalance as a coronal shift more than $2 \mathrm{~cm}$ and they have not been able to find a significant correlation between neuroaxial abnormalities and coronal imbalance. In our study, the mean of transverse coronal shift from plumb line was $18.5 \mathrm{~mm}$ (range 0 to $56 \mathrm{~mm}$ ) in patients without abnormalities which was significantly lesser than those who had neuroaxial abnormalities with the mean of $37.6 \mathrm{~mm}$ (range 34 to $41 \mathrm{~mm})(P=0.02)$. We considered coronal imbalance when lateral shift of the spine was more than $15 \mathrm{~mm}$ to increase the sensitivity of selection criteria. Forty-six patients (32\%) have had $15 \mathrm{~mm}$ or more coronal imbalance. Thirteen of these patients have had neuroaxial abnormalities. Two third of patients with abnormal MRI findings have had coronal imbalance. The severity of coronal imbalance could predict existing neuroaxial abnormalities but neither the severity of neuroaxial problem, nor the necessity of neurosurgical intervention. The significance of the correlation between severe coronal imbalance and/or severe lumbar or TL curves with MRI detected abnormalities, has not been well studied. We think that the discordance between our study and that of Lee et al. is due to the inclusion criteria and the way to define the coronal imbalance.
The headache or backache were not evaluated in our study. It is unusual for an adolescent patient with true idiopathic scoliosis to have significant pain. Scoliosis associated with chronic, disabling pain or pain that awakens the patient at night has been associated with tumors in the spine and spinal cord and warrants further investigation. Morcuende et al. [35] reported 13 scoliosis patients who underwent MRI because of pain. None of them had an abnormal MRI, and none of their patients who had syringomyelia and Arnold-Chiari type I malformations complained of headache or neck pain.

Regarding neurologic examination, only the patients with subtle neurologic findings were included in the study. The others have been referred to the neurosurgery consultation and were not included in the study. There were 6 patients who have had ASAR. All of them have been found to have abnormal neuroaxial finding on their MR imaging. All but one of them were operated by neurosurgeon for extensive syringomyelia or associated Arnold Chiari malformation. Otherwise, eleven patients with abnormal neuroaxial abnormalities (70\%) have had normal neurologic examination. This incoherency between abnormal MR findings and physical examination has been reported up to $60 \%$ patients with scoliosis secondary to syringomyelia or Chiari malformations [32,36,37]. The clinical significance of syringomyelia or Chiari malformations without any neurologic signs is not fully understood. These patients, who had normal clinical examination with neuroaxial anomaly, underwent arthrodesis without any neurologic complication.

It has been concluded that the most valuable indicator of a surgically important abnormality of the central nervous system is presence of ASAR, and may follow by the presence of a coronal shift. Physical examination findings and subtle clues on diagnostic imaging may help the orthopaedic surgeon diagnose scoliosis associated with syringomyelia or Arnold-Chiari malformation. However, the cause and effect of these neurological abnormalities and scoliosis is not well established. Early age at the onset and structural lumbar or thoracolumbar curves should also consider as a risk factor. The other factors should be studied in a larger series of patients.

\section{Competing interests}

The authors declare that they have no competing interests.

\section{Authors' contributions}

MK: carried out the study design, gathering data and analyzed them. SS: interpreted all MRIs and X-rays. KM: directed the study, formulated the results and drafted the discussion section. All authors read and approved the final manuscript.

\section{Author details}

${ }^{1}$ Talegani Hospital, Shahid Beheshti University of Medical Sciences, Tehran, Iran. ${ }^{2}$ Imam Hosein Hospital, Shahid Beheshti University of Medical Sciences, Tehran, Iran. ${ }^{3}$ Robert Debre Hospital, Paris 7 University, Paris, France. 
Received: 6 March 2014 Accepted: 30 June 2014

Published: 19 July 2014

\section{References}

1. Noordeen $\mathrm{MH}$, Taylor BA, Edgar MA: Syringomyelia: a potential risk factor in scoliosis surgery. Spine 1994, 19:1406-1409.

2. Ozerdemoglu RA, Denis F, Transfeldt EE: Scoliosis associated with syringomyelia: clinical and radiologic correlation. Spine 2003, 28:1410-1417.

3. MacEwen GD, Bunnell WP, Sriram K: Acute neurological complications in the treatment of scoliosis: a report of the Scoliosis Research Society. J Bone Joint Surg Am 1975, 57:404-408.

4. Peer S, Krismer M, Judmaier W, Kerber W: The value of MRI in the preoperative assessment of scoliosis. Orthopade 1994, 23:318-322.

5. Stokes IAF: Three-dimensional terminology of spinal deformity: a report presented to the Scoliosis Research Society by the Scoliosis Research Society Working Group on 3-D terminology of spinal deformity. Spine 1994, 19:236-248.

6. Lenke LG, Betz RR, Harms J, Bridwell KH, Clements DH, Lowe TG, Blanke K: Adolescent idiopathic scoliosis: a new classification to determine extent of spinal arthrodesis. J Bone Joint Surg Am 2001, 83:1169-1181.

7. King HA, Moe JH, Bradford DS, Winter RB: The selection of fusion levels in thoracic idiopathic scoliosis. J Bone Joint Surg Am 1983, 65:1302.

8. Evans SC, Edgar MA, Hall-Craggs MA, Powell MP, Taylor B, Noordeen H: MRI of 'idiopathic' juvenile scoliosis: a prospective study. J Bone Joint Surg (Br) 1996, 78:314-317.

9. Lewonowski K, King JD, Nelson MD: Routine use of magnetic resonance imaging in idiopathic scoliosis patients less than eleven years of age. Spine 1992, 17(Suppl):109-116.

10. Winter PD, Lonstein JE, Heithoff KB, Kirkham JA: Magnetic resonance imaging evaluation of the adolescent patient with idiopathic scoliosis before spinal instrumentation and fusion: a prospective, double-blinded study of 140 patients. Spine 1997, 22:855-858

11. Barnes PD, Brody JD, Jaramillo D, Akbar JU, Emans JB: Atypical idiopathic scoliosis: MR imaging evaluation. Radiology 1993, 186:247-253.

12. Schwend RM, Hennrikus W, Hall JE, Emans JB: Childhood scoliosis: clinical indications for magnetic resonance imaging. J Bone Joint Surg Am 1995, 77:46-53.

13. Coonrad R, Richardson WH, Oakes WJ: Left thoracic curves can be different. Orthop Trans 1985, 9:126-127.

14. Sutterlin CE, Grogan DL, Ogden JA: Diagnosis of developmental pathology of the neuraxis my magnetic resonance imaging. J Pediatr Orthop 1987, 7:291-297.

15. Beertrand SL, Drvaric DM, Roberts JM: Scoliosis in syringomyelia. Orthopaedics 1989, 12:335-337.

16. Maiocco B, Deeney VF, Coulon R, Parks PF Jr: Adolescent idiopathic scoliosis and the presence of spinal cord abnormalities. Preoperatve magnetic resonance imaging analysis. Spine 1997, 22:2537-2541.

17. Tashiro K, Fukazawa T, Moriwaka F, Hamada T, Isu T, Iwasaki Y, Abe H: Syringomyelia syndrome: clinical features in 31 cases confirmed by CT myelography or magnetic resonance imaging. J Neurol 1987, 235:26-29.

18. Tokunaga M, Minami S, Isobe K, Moriya H, Kitahara H, Nakata Y: Study on the scoliosis complicated with syringomyelia. Spinal Deformity 1997, 22:855-888.

19. Loder RT, Stasikelis P, Farley FA: Sagittal profiles of the spine in scoliosis associated with an Arnold-Chiari malformation with or without syringomyelia. J Pediatr Orthop 2002, 22:483-491.

20. Whitaker C, Schoenecker PL, Lenke LG: Hyperkyphosis as an indicator of syringomyelia in idiopathic scoliosis: a case report. Spine 2003, 28:E16-E20.

21. Zadeh HG, Sakka SA, Powell MP, Mehta M: Absent superficial abdominal reflexes in children with scoliosis. J Bone Joint Surg (Br) 1995, 77:762-767.

22. Gupta P, Lenke LG, Bridwell KH: Incidence of neural axis abnormalities in infantile and juvenile patients with spinal deformity. Spine 1998, 23:206-210.

23. Geissele AE, Kransdorf MJ, Geyer CA, Jelinek MJS, Van Dam LBE: Magnetic resonance imaging of the brain stem in adolescent idiopathic scoliosis. Spine 1991, 16:761-763.

24. Mejia EA, Hennrikus WL, Schwend RM, Emans JB: A prospective evaluation of idiopathic left thoracic scoliosis with magnetic resonance imaging. J Pediatr Orthop 1996, 16:354-358.

25. Shen WJ, McDowell GS, Burke SW, Levine DB, Chutorian AM: Routine preoperative MRI and SEP studies in adolescent idiopathic scoliosis. J Pediatr Orthop 1996, 16:350-353.
26. Dobbs MB, Lenke LG, Szymanski DA, Morcuende JA, Weinstein SL, Bridwell KH, Sponseller PD: Prevalence of neural axis abnormalities in patients with infantile idiopathic scoliosis. J Bone Joint Surg Am 2002, 84:2230-2234.

27. Ouellet JA, LaPlaza J, Erickson MA, Birch JG, Burke S, Browne R: Sagittal plane deformity in the thoracic spine: a clue to the presence of syringomyelia as a cause of scoliosis. Spine 2003, 28:2147-2151.

28. Do T, Fras C, Burke S, Widmann RF, Rawlins B, Boachie-Adjei O: Clinical value of routine preoperative magnetic resonance imaging in adolescent idiopathic scoliosis: a prospective study of three hundred and twenty-seven patients. J Bone Joint Surg Am 2001, 83:577-579.

29. Davids JR, Chamberlin E, Blackhurst DW: Indications for magnetic resonance imaging in presumed adolescent idiopathic scoliosis. J Bone Joint Surg Am 2004, 86:2187-2195.

30. Inoue M, Minami S, Nakata Y, Otsuka Y, Takaso M, Kitahara H, Moriya H: Preoperative MRI analysis of patients with idiopathic scoliosis: a prospective study. Spine 2005, 30:108-114.

31. Nakahara D, Yonezawa I, Kobanawa K, Sakoda J, Nojiri H, Kamano S, Kurosawa $\mathrm{H}$ : Magnetic resonance imaging evaluation of patients with idiopathic scoliosis: a prospective study of four hundred seventy-two outpatients. Spine 2011, 36:E482-E485.

32. Rajasekaran S, Kamath V, Kiran R, Shetty AP: Intraspinal anomalies in scoliosis: an MRI analysis of 177 consecutive scoliosis patients. Indian J Orthop 2010, 44:57-63.

33. Lee RS, Reed DW, Saifuddin A: The correlation between coronal balance and neuroaxial abnormalities detected on MRI in adolescent idiopathic scoliosis. Eur Spine J 2012, 21:1106-1110.

34. Qiao J, Zhu Z, Zhu F, Wu T, Qian B, Xu L, Qiu Y: Indication for preoperative MRI of neural axis abnormalities in patients with presumed thoracolumbar/lumbar idiopathic scoliosis. Eur Spine 2013, 22(2):360-366

35. Morcuende JA, Dolan LA, Vazquez JD, Jirasirakul A, Weinstein SL: A prognostic model for the presence of neurogenic lesions in atypical idiopathic scoliosis. Spine 2004, 29(1):51-58

36. Charry O, Koop S, Winter R, Lonstein J, Denis F, Bailey W: Syringomyelia and scoliosis: a review of twenty-five pediatric patients. J Pediatr Orthop 1994, 14:309-317.

37. Park JK, Gleason PL, Madsen JR, Goumnerova LC, Scott RM: Presentation and management of Chiari I malformation in children. Pediatr Neurosurg 1997, 26:190-196.

doi:10.1186/1748-7161-9-9

Cite this article as: Karami et al:: Evaluation of coronal shift as an indicator of neuroaxial abnormalities in adolescent idiopathic scoliosis: a prospective study. Scoliosis 2014 9:9.

\section{Submit your next manuscript to BioMed Central and take full advantage of:}

- Convenient online submission

- Thorough peer review

- No space constraints or color figure charges

- Immediate publication on acceptance

- Inclusion in PubMed, CAS, Scopus and Google Scholar

- Research which is freely available for redistribution 